\title{
Shell shape variation in populations of common cockle Anadara oceanica (Lesson, 183I) (Bivalvia Arcidae) from the intertidal areas of Margosatubig, Zamboanga del Sur (Philippines)
}

\author{
Ranjiv D.Alibon "*,Alea Ester T. Ordoyo', Jessa Mae P. Gonzales', Melbert C. Sepe', Mark Anthony J.Torres ${ }^{3}$ \\ \& Genelyn G. Madjos ${ }^{1,2}$ \\ ${ }^{1}$ Department of Biological Sciences, College of Science and Mathematics, Western Mindanao State University, Zamboanga \\ City, Philippines \\ ${ }^{2}$ Research Utilization, Publication and Information Dissemination Office, Western Mindanao State University, Zamboanga \\ City, Philippines \\ ${ }^{3}$ Department of Biological Sciences, College of Science and Mathematics, Mindanao State University - Iligan Institute of \\ Technology, Iligan City, Philippines \\ ${ }^{*}$ Corresponding author, email:ranjalibon@gmail.com
}

ABSTRACT The advent of geometric morphometrics opened an area to study morphological variations in organisms. Thus, the aim of this study is to use outline-based geometric morphometrics to describe variations in the shell shapes of the left and right valves of Anadara oceanica (Lesson, 1831) (Bivalvia Arcidae) populations from the two neighbouring intertidal zones of Margosatubig, Zamboanga del Sur, Philippines. Herein, there were two levels of analyses that were employed: first, the shell shapes of the outer left and right valves between populations were compared; second, the shell shapes within population were quantitatively determined in terms of its symmetry. Results revealed significant variations both in the left and right valves of $A$. oceanica between populations. The variations observed are characterized by the deformations in the umbonal and anteroventral angles and in the dorsal, anterior and ventral margins of the outer shell both in the left and right valves. Although further studies are necessary in order to elucidate these variations, the second analysis revealed that the detected asymmetry in the shell shapes within A. oceanica populations was the cause of variation within populations that contributed to the significant variations between populations. Considering that the two sites are not geographically isolated, the results herein clearly proved that shell shape variation could also occur in neighbouring populations. The variations in the shell shapes of $A$. oceanica populations may have implications to habitat adaptation which aid in understanding the nature of this species especially those dwelling in the intertidal areas of Margosatubig, Zamboanga del Sur, Philippines.

KEY WORDS Asymmetry; environmental conditions; geometric morphometrics, habitat adaptation; neighbouring populations.

Received 01.04.2020; accepted 26.05.2020; published online 18.09.2020

\section{INTRODUCTION}

The common cockle, Anadara oceanica (Lesson, 1831), = maculosa (Reeve, 1844), (Bivalvia Arcidae) is characterized by its trapezoidal ribbed shells with a heavy periostracum and taxodont hinge. It is commonly called as cockle as it morphologically resembles the European cockle Cerastoderma edule (Linnaeus, 1758) (Bivalvia Cardiidae) which in fact belongs to the family Cardiidae. Thus, 
this terminology does not have any taxonomic significance. Further, it is also called blood clam because of its specialised invariable occurrence of red blood pigments haemoglobin (Davenport \& Wong, 1986). It typically occurs in habitats ranging from the intertidal zone on wave exposed sandy shores to the marginally subtidal areas of sheltered mudflats up to the higher tidal levels within the mangrove areas and even extend into deeper subtidal areas (Brotohadikusumo, 1994). Due to the absence of well-developed siphons, A. oceanica is considered as a poor burrower, meaning it cannot delve in the substrate at any depths (Brotohadikusumo, 1994). This poor burrowing behaviour of A. oceanica makes it highly exposed in receiving high concentrations of natural and anthropogenic wastes in the intertidal zones such as inorganic and organic nutrients, soil and sediments, and pollutants (Sithik et al., 2009). Just like other bivalves, $A$. oceanica has limited mobility that restricts its ability to avoid adverse conditions due to its sedentary behaviour (Sharma et al., 2016). Hence, populations of this species are good candidates for the detection of different types and levels of stress.

Due to the fact that shell is the most variable part of a bivalve species and is largely affected by environmental conditions (Uba et al., 2019), it has been the most widely used part in studying Anadara species, specifically by focusing on shell shape variation. Succeeding studies in Anadara species supported significant shell shape variation within and between populations (Mzighani, 2005; Faulkner, 2010; Lodola et al., 2011; Finogenova et al., 2013; Souji \& Radhakrishnan, 2015; Aydin et al., 2014; Qonita et al., 2015; Meshram \& Mohite, 2016). These studies, among others, focused on traditional approaches in morphometric studies (i.e., analysis of linear distances). However, these methods have some statistical disadvantages such as the difficulty in acquiring size-free shape variables from individuals as these measurements are highly correlated with size (Morais et al., 2014). With this, it is pertinent to search an applicable tool that can reliably analyze shape variability and the advent of geometric morphometrics (i.e., outline-based analysis) has come as its solution. This quantitative tool is used to determine and compare morphological shape variations of biological structures (Sansom, 2009). Thus, this method was employed in this study and is particularly advantageous compared to the traditional method because it effectively avoids confusion between size and shape by preserving the shape variables and the main geometric properties of the samples (Webster \& Sheets, 2010).

It is hypothesized that shell shape variation is an adaptive strategy of bivalves in response to its current ecological conditions (Alibon et al., 2018). Thereby, shell shape variations in A. oceanica populations may have implications to habitat adaptation which can help in understanding the nature of this species especially those dwelling in the intertidal zones of Margosatubig, Zamboanga del Sur, Philippines. Accordingly, pollution of marine water caused by improper disposal of residential wastes and rural run-offs is one of the main ecological concerns in this locality and that the presence of $A$. oceanica in this area suggests a tolerance to the current ecological conditions that could be influencing its shell shape. Thus, this study was conceptualized with the aim to describe variations in the shell shapes of $A$. oceanica into two levels of analyses. First, the shell shapes of the outer left and right valves between the two different A. oceanica populations from Margosatubig were compared using outline-based geometric morphometrics. Second, the shell shape of $A$. oceanica within population was scored for differences in shapes between its left and right valves, otherwise known as fluctuating asymmetry which is a potential bioindicator of environmental stress in populations (Trono et al., 2015).

\section{MATERIAL AND METHODS}

\section{Description of sampling sites and collection of samples}

A total of 60 adult $A$. oceanica individuals with a similar size range of 40-50 millimeter shell length were handpicked purposively from each of the two neighbouring intertidal areas in the municipality of Margosatubig, province of Zamboanga del Sur, in the Philippines; Tulog-bato, Barangay Tiguian $\left(7^{\circ} 34^{\prime} \mathrm{N}, 123^{\circ} 10^{\prime} \mathrm{E}\right)$ and Samboang, Barangay Poblacion $\left(7^{\circ} 35^{\prime} \mathrm{N}, 123^{\circ} 10^{\prime} \mathrm{E}\right)$ shown in figure 1 . Margosatubig is bounded on the north by the $\mathrm{Mu}$ nicipality of Lapuyan, on the east by the Municipality of Dimataling, on the west by the Municipality of Malangas and on the south by the Municipality of Vincenzo Sagun. 


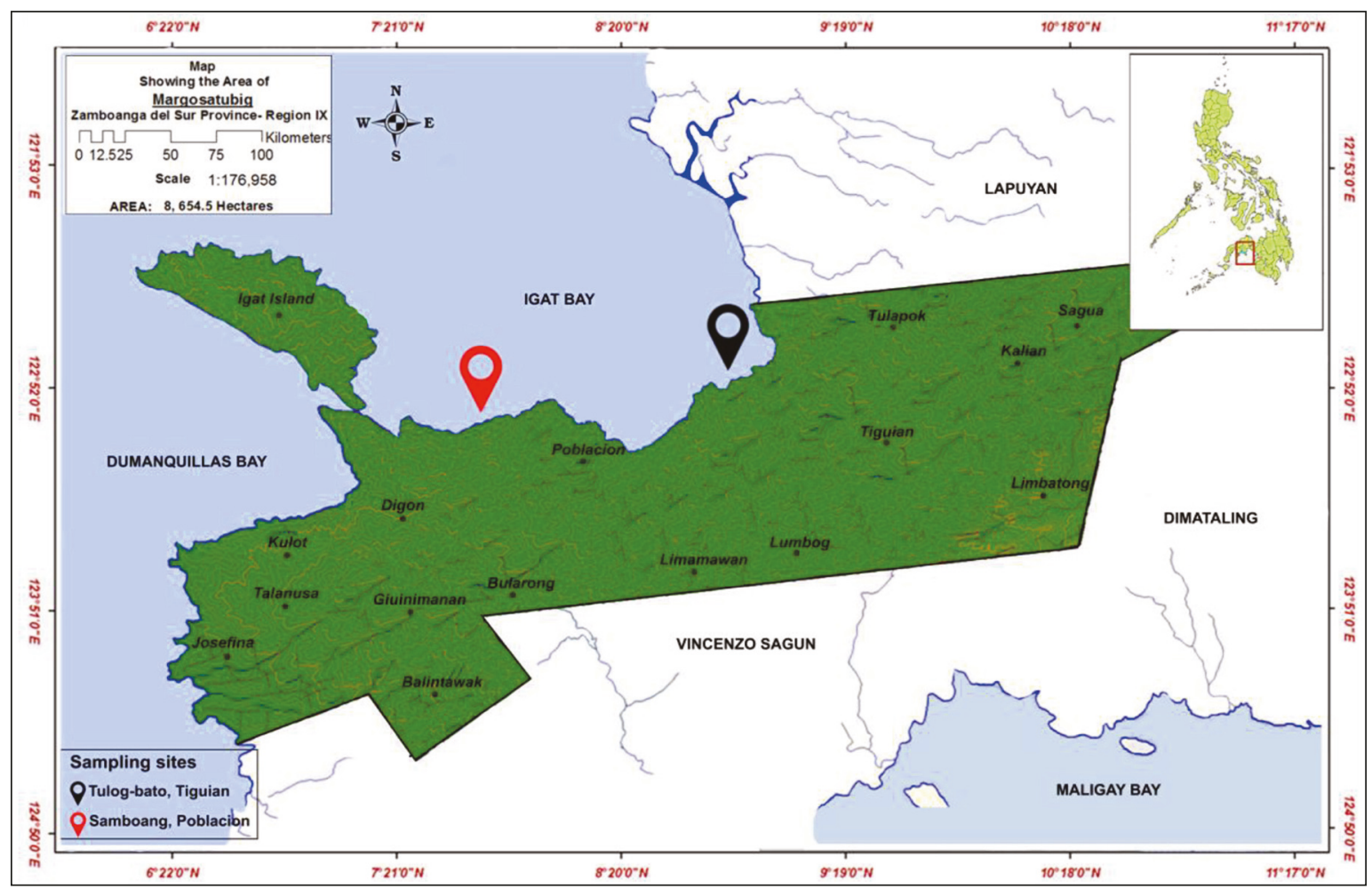

Figure 1. Map of Margosatubig, Zamboanga del Sur (Philippines) showing the location of the two sampling sites.

Margosatubig is one of the coastal municipalities of Dumanquillas Bay and Igat Bay in the province of Zamboanga del Sur which in a way it embodies dynamic ecosystems such as a mangrove estuarine ecosystem (Tulog-bato, Barangay Tiguian) and a residential intertidal area (Samboang, Barangay Poblacion). The coastline in Tulog-bato is characterized by mudflats and muddy shores with thick patches of mangroves that are partially enclosed with coastal body of water formed where freshwater from the upper land meets with saltwater, a characteristic of a mangrove estuarine ecosystem. Contrarily, the coastline in Samboang is characterized by tidal flats and sandy shores and is dominated with residential houses where gravels, coarse and sandy sediments are readily observed from the shore to the intertidal zones that are exposed to air at low tide and covered with seawater when the tide is high. It is prominent that rapidly moving water tends to carry larger and heavier sediment particles washing away smaller particles and preventing their deposition. Hence, tidal flats with low energy water movement are characterized by more muddy sediments such as that of in Tulog- bato whereas in higher energy regimes with stronger currents and moderate wave action, the flats are generally composed of courser sandy/muddy sediments similar to that in Samboang. The taxonomy follows WoRMS (2020).

\section{Preparation and imaging of samples}

The samples were cleaned off from their soft tissues before the shells were sun-dried. The umbonal angle is distinguished clearly in the outer valve (Fig. 2). The left and right valves are identified in the inner valve based on the position of its pallial sinus wherein the left valve's pallial sinus curves to the left and the right valve's pallial sinus curves to the right (Fig. 3). The outer left and right valves of A. oceanica were oriented in the same position, respectively. Then, samples were photographed using Nikon D7000 with a pixel size of $4.78 \mu \mathrm{m}$ ensuring that the samples and the lens of the camera were at uniform focusing distance of $0.8 \mathrm{~m}$. Images of the samples were triplicated in order to minimize source of error and bias and then numbered respectively to identify the sequence of the samples. 
Outline-based data acquisition and statistical
analyses

A total of 100 points were established for the outline curve of the outer left valve (Fig. 4) and right valve (Fig. 5) contour in 1 using tpsDig version 1.36. After processing of outline curve, the thin plate splines (TPS) curve was converted into landmark points or XY coordinates using tpsUtil version 1.36 to build TPS file and make link files (Rohlf, 2004). The raw landmark coordinates are first superimposed using Generalized Procrustes Super Position Algorithm, whereby the sum of squared distances between each object and a reference configuration (consensus) are iteratively minimized by translations and rigid rotation (Khiaban et al., 2010). The partial warp (Generalized Procrustes Super Position Algorithm) scores of these superimposed data are used as shape variables (Sepe et al., 2019). The TPS interpolation function derived from the mean of the superimposed data is applied to a squared grid overlaying the mean landmark configuration to provide a direct and quantitative implementation. The consensus shape data of each separate groups are measured by relative warps ordinations plots using tpsRelw version 1.36. The RW scores are computed from the partial warps (Rolhf, 2004).

To statistically test the hypothesis that the shell shapes of $A$. oceanica populations vary between the two sites, Multivariate Analysis of Variance (MANOVA) was used based on the generated RW scores for the shape of $A$. oceanica populations using Paleontological Statistics (PAST) version 3.0 Software, results with $\mathrm{p}<0.05$ are considered statistically significant. MANOVA is a form of multivariate measure which tests whether several samples have the same mean shape (Sepe \& Demayo, 2014; Madjos \& Anies, 2016). Canonical Variate Analysis (CVA) was done using the same version of the software mentioned above to determine variations among groups relative to the pooled within group variation generated from the RW scores and the canonical variates displayed as an ordination and were scattered within groups (Hammer et al., 2001; Madjos et al., 2015).

\section{Measurement of asymmetry levels}

The analysis of asymmetry in the shell shapes of $A$. oceanica was based on matching symmetry considering that the left and right valves are pairs of separated structures (Savriama \& Klingenberg, 2011). Consequently, the reflection was removed by transforming all configurations from one body side to their mirror images (Klingenberg et al., 2002). After the conversion of the outline TPS curve into landmark points or XY coordinates using tpsUtil version 1.36 (Rohlf, 2004), Symmetry and Asymmetry in Geometric Data (SAGE) Program version 1.04 was then used to evaluate the fluctuating asymmetry (FA) levels of the $\mathrm{x}$ and $\mathrm{y}$ coordinates of the landmarks per individual using a configuration protocol (Marquez, 2014). Procrustes superimposition analysis was performed with the original and mirrored configurations of the shells, simultaneously.

A Two-Way, Mixed-Model Analysis of Variance (ANOVA) was used to test the significance of the following effects: Individuals, Sides, Individuals $\mathrm{x}$ Sides. The effect called Individuals refers to the variation among individual genotypes while the Individuals mean square is a measure of total phenotypic variation. The effect called Sides refers to the variation between the two sides and it is a measure of directional asymmetry. The Individuals x Sides interaction is the failure of the effect of individuals to be the same from side to side otherwise known as fluctuating asymmetry. The error term is also included as effect which is the Measurement Error and it is a random effect (Graham et al., 2010; Alibon et al., 2019). In addition, Principal Component Analysis (PCA) was performed in the same software to detect the components of variances and deviations for the samples to carry out an interpolation based on a TPS and then visualize shape changes as landmark displacement in the deformation grid (Marquez, 2014).

\section{RESULTS AND DISCUSSION}

Bivalves are considered as bioindicators of the coastal ecosystem. As bioindicators, they can serve as functional measures of exposure to various stressors which help to detect early warning system declines in environmental quality and population health (Adams et al., 2004). In this study, we hypothesized that the varying anthropogenic disturbances brought about by the continuous destruction in mangrove ecosystem and improper disposal of residential wastes in the intertidal areas of Mar- 
gosatubig have contributed to the deterioration of the quality of the habitat subjecting $A$. oceanica to ecological stress, thereby, promoting morphological variation in the shell shapes of this species.

Herewith, significant variations were observed in the shell shape of the left and right valves of $A$. oceanica between the two populations based from the results of MANOVA (Table 1). Thin plate splines of the mean shell shapes of $A$. oceanica between the two populations show visual illustrations where the variations could be observed (Figs. 6, 7). The distribution of individuals among the two populations of $A$. oceanica in the CVA plot shows how each population differs in terms of its shell shape (Fig. 8). It was clear from these results that both valves of $A$. oceanica exhibited shape variations among the two populations. Such variations are characterized by major variances in the umbonal and anteroventral angles and in the dorsal, anterior and ventral margins of the outer shell both in the left and right valves.
Between populations, left valves in Tulog-bato have expanded umbonal angle and slightly curved anteroventral angle while those in Samboang have compressed umbonal angle and pronouncedly curved anteroventral angle. On one hand, right valves in Tulog-bato population have largely expanded umbonal angle and pronouncedly curved anteroventral angle while those in Samboang population have largely compressed umbonal angle and outwardly protruding anteroventral angle. In the inner surface of bivalve shell, a mark called the pallial line lies in its surface more or less parallel with the anteroventral angle, thus, the variation observed in the anteroventral angle of $A$. oceanica could be affected by the differences in the pallial line of the inner valve (Markus, 2010).

Noticeably, the position of the outline in the left valve along the anterior margin among Tulog-bato population bends closer to the posterior fold of the shell resulting to shorter ventral margin and compressed dorsal margin compared to the elongated

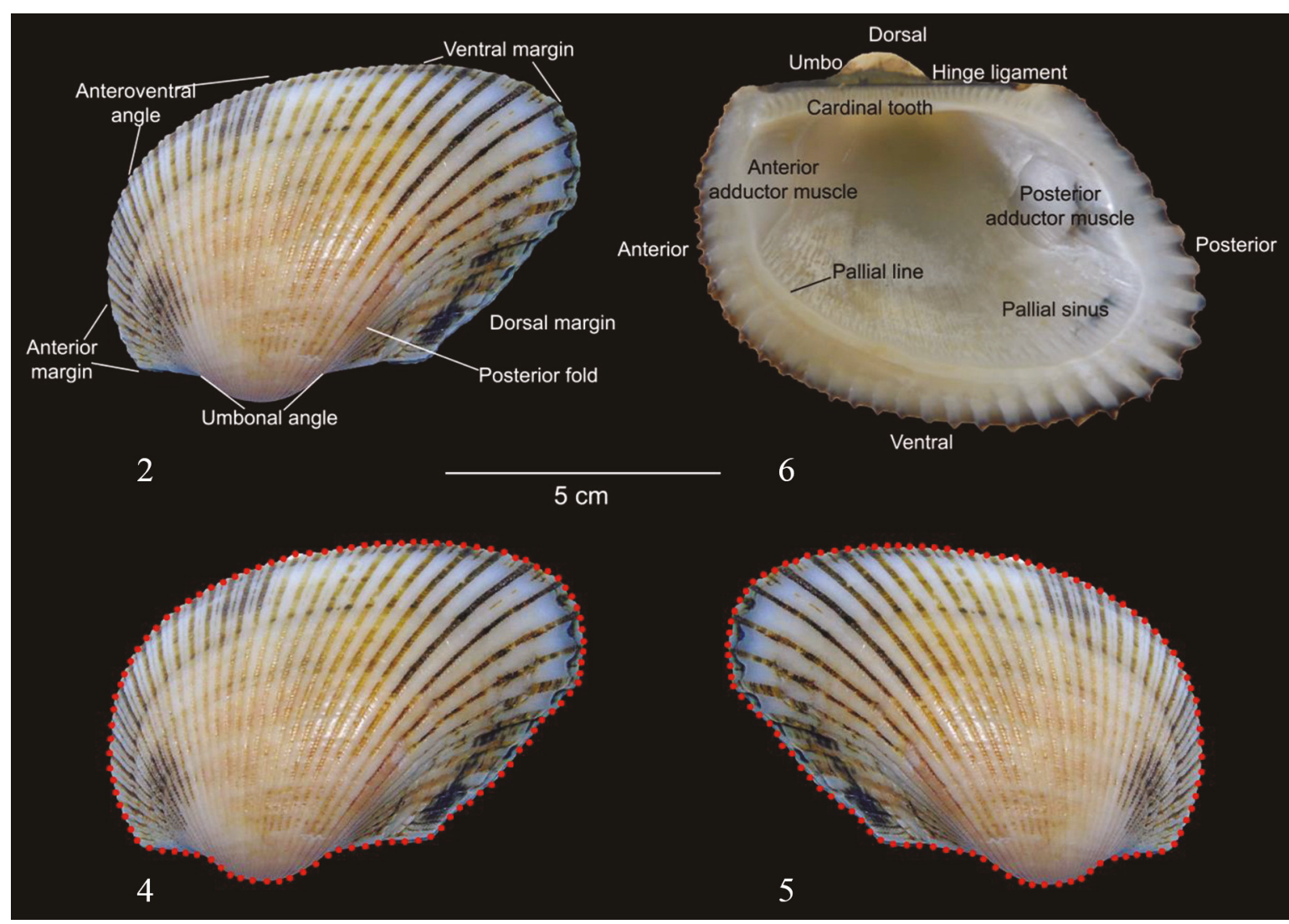

Figures 2-5. Image of A. oceanica showing its (Fig. 2) outer and (Fig. 3) inner left valve and the outline in the (Fig. 4) left valve and (Fig. 5) right valve. 
ventral margin and expanded dorsal margin of Samboang population since its anterior margin bends away to the posterior fold of the shell. In bivalve shells, anterior portions are shorter than the posterior (Tan et al., 2015). The same condition was observed in the anterior and dorsal margins of the right valves in Samboang population, thus the position of the outline in these margins are affected which move closer to the posterior fold making its ventral margin tightly compressed compared to the elongated ventral margin of Tulog-bato population since its dorsal and anterior margins bend away to the posterior fold.

The CVA scatter plot was produced from relative warp scores based on the pooled populations of A. oceanica. As shown in Figure 4, it illustrates the overlapping in the shell shape of the left and right valves of $A$. oceanica among the two populations, indicating that some individuals of $A$. oceanica have shown shell shape similarities in certain morphological aspects and that shell shape variations occurred herein can be attributed to the morphological distinctness of the individuals shell shape examined within population which have contributed significantly to the shape variances between populations (Peñaredondo \& Demayo, 2017; Madjos \& Demayo, 2018).

Disparities in the shell shapes were further visualized using the two varying deviated transformation grids: the negatively (-) and positively $(+)$ deviated grids. Each deviation represents one or more population that tend towards the negative or positive deviation or near to the mean/consensus deviation of the morphological shape. Relative distribution of the variances are projected as boxplot that provides decisive criterion in selecting which population best assumes the form with respect to the mean shape (Sepe \& Demayo, 2017). The variations observed using the method of relative warps obtained three (3) and four (4) significant relative warp scores for the left and right valves, respectively. The variations are shown in the form of boxplots, consensus morphology and frequency histograms for the left and right valves (Figs. 9, 10). The descriptions of the shell shape variation based on the significant RW scores in the pooled population of A. oceanica are discussed in Table 2.

In the left valve, the range of the boxplot of RW1 in Tulog-bato population spreads along the negative axis while Samboang population slightly spreads along the positive axis which indicates that Tulog-bato population resembles the morphology explained in the negative axis while Samboang population reflects the morphology explained in positive axis. In both populations, the range of the boxplots of RW2 deviates towards negative axis while the range of boxplots of RW3 deviates towards positive axis. For the right valve, the range of the boxplot of RW1 in Tulog-bato population is found lying on the positive axis while Samboang population lies slightly along the negative axis which indicates that Tulog-bato population resembles the morphology explained in the positive axis while Samboang population reflects the morphology explained in negative axis. In both populations, the range of the boxplots of the RW2 and RW3 are skewed along the negative axis while the boxplot of the RW4 is skewed in positive axis.

Further analysis in the shell shapes of $A$. oceanica within population in terms of its symmetry was done through Procrustes Two-Way, Mixed-Model ANOVA to quantitatively determine the asymmetry levels in A. oceanica (Table 3 ). In both populations, the Individuals $x$ Sides interaction yield significant $p$-value $(p<0.001)$, suggesting that the differences in the shapes between the left and right valves can be attributed to the failure of the effect of individual valves to be the same from side to side. Thus, this indicates fluctuating asymmetry in A. oceanica population. However, a considerably higher significant FA value was reflected in Samboang population $(\mathrm{F}=1.8904, \mathrm{p}=0.0000)$ compared in Tulog-bato population $(\mathrm{F}=0.9572, \mathrm{p}=0.0000)$, this implies that two different populations might have experienced varying ecological stress in their respective habitat and that it could be argued that Samboang populations are more ecologically stressed compared to the Tulog-bato populations (Palmer, 1994). The measured asymmetry in $A$. oceanica herein supports the idea that the valves of Anadara species are inequivalve wherein the left valves are usually larger than the right valves (Finogenova et al., 2013; Strafella et al., 2018). This random deviation in the symmetry of an organism such as in the case of $A$. oceanica has been hypothesized to be the result of the genome to protect the organism against stressors during development (Swaddle, 2003).

As illustrated by the principal components, the red dots in the grid represent the morphological landmarks used while the blue arrows symbolize 


\begin{tabular}{|lcccccc|}
\hline \multicolumn{1}{|c}{ Valves } & Wilk's lambda & Pillai trace & df1 & df2 & F & $\boldsymbol{p}$ value \\
\hline Left valve & 0.6028 & $0.3972 \mathrm{E}-08$ & 4 & 175 & 28.83 & $2.0830 \mathrm{E}-18^{*}$ \\
Right valve & 0.4469 & $1.474 \mathrm{E}-08$ & 4 & 175 & 54.14 & $1.2263 \mathrm{E}-29 *$ \\
\hline *Significant at $\alpha=0.05$ & & & & & \\
\hline
\end{tabular}

Table 1. Results of Multivariate Analysis of Variance based on significant relative warp scores for significant variation in the shape of the left and right valves of $A$. oceanica between the two populations.

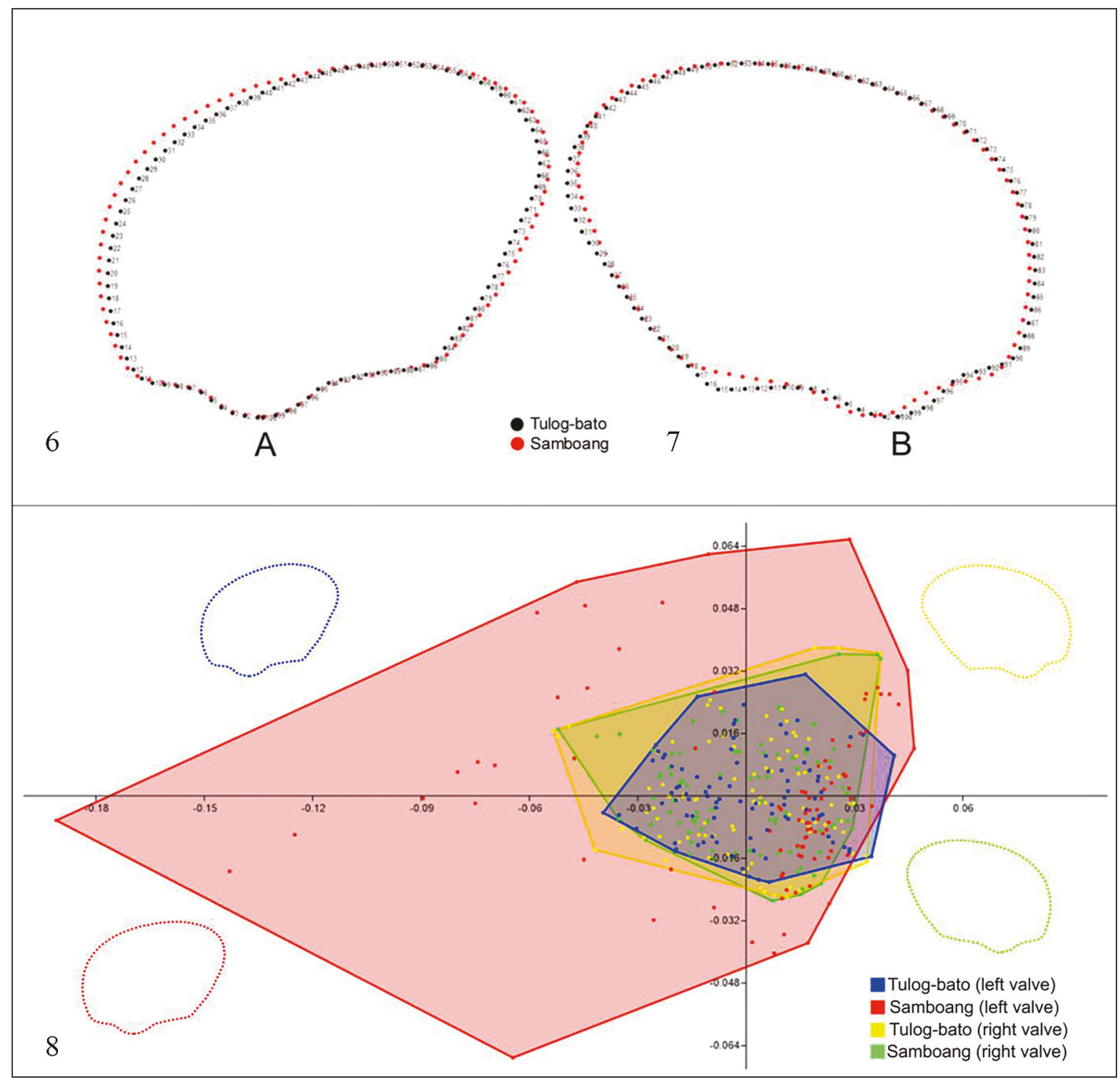

Figures 6, 7. Conchological mean shape variations of the (Fig. 6) left and (Fig. 7) right valves of A. oceanica between the two populations. Figure 8. Canonical Variate Analysis scatter plot showing the distribution of shell shapes between the two populations of $A$. oceanica based on significant relative warp scores. 


\begin{tabular}{|c|c|c|}
\hline Relative warp & Left valve & Right valve \\
\hline RW1 & $\begin{array}{l}\text { Variation accounts about } \mathbf{4 6 . 7 8 \%} \\
\text { (-) The umbonal angle is compressed while the an- } \\
\text { teroventral angle is pronouncedly curved. The dorsal } \\
\text { and anterior margins bend closer to the posterior fold } \\
\text { making its ventral margin elongated. } \\
\text { (+) The umbonal angle is expanded while the ante- } \\
\text { roventral angle is slightly curved. The dorsal and an- } \\
\text { terior margins bend away to the posterior fold } \\
\text { resulting to shortened ventral margin. }\end{array}$ & $\begin{array}{l}\text { Variation accounts about } \mathbf{4 8 . 7 8 \%} \\
\text { (-) The umbonal angle is largely expanded while the } \\
\text { anteroventral margin bends inward. The dorsal and } \\
\text { anterior margins bend away to the posterior fold } \\
\text { making its ventral margin compressed. } \\
\text { (+) The umbonal angle is compressed while the an- } \\
\text { teroventral angle is pronouncedly curved. The dorsal } \\
\text { and anterior margins bend closer to the posterior fold } \\
\text { resulting to elongated ventral margin. }\end{array}$ \\
\hline RW2 & $\begin{array}{l}\text { Variation accounts about } \mathbf{2 0 . 3 8 \%} \\
\text { (-) The umbonal angle bends towards dorsal margin } \\
\text { while the anteroventral angle curved pronouncedly. } \\
\text { The anterior margin bends closer to the posterior fold } \\
\text { resulting to compressed dorsal margin and shortened } \\
\text { ventral margin. } \\
\text { (+) The umbonal angle bends towards anterior mar- } \\
\text { gin while the anteroventral angle curved slightly. The } \\
\text { anterior margin bends away to the posterior fold } \\
\text { making its dorsal margin expanded and ventral mar- } \\
\text { gin elongated. }\end{array}$ & $\begin{array}{l}\text { Variation accounts about } \mathbf{1 4 . 3 3 \%} \\
\text { (-) The umbonal angle is compressed while the an- } \\
\text { teroventral angle protrudes outward. The dorsal and } \\
\text { anterior margins are shortened and bend closer to the } \\
\text { posterior fold making its ventral margin elongated } \\
\text { and it protrudes outward. } \\
\text { (+) The umbonal angle is tightly compressed while } \\
\text { the anteroventral angle and ventral margin bend } \\
\text { inward. Anterior margin is tightly compressed away } \\
\text { to the posterior fold making its dorsal margin elon- } \\
\text { gated. }\end{array}$ \\
\hline RW3 & $\begin{array}{l}\text { Variation accounts about } \mathbf{7 . 2 7 \%} \\
\text { (-) The umbonal angle is expanded while the ante- } \\
\text { roventral angle is compressed. The dorsal margin sli- } \\
\text { ghtly bends towards the posterior fold making its } \\
\text { anterior margin pronouncedly curved and its ventral } \\
\text { margin elongated. } \\
\text { (-) The umbonal angle is expanded while the ante- } \\
\text { roventral angle is curved. Anterior margin bends } \\
\text { away to the posterior fold making its dorsal margin } \\
\text { slightly compressed and its ventral margin elongated. }\end{array}$ & $\begin{array}{l}\text { Variation accounts about } \mathbf{1 0 . 1 2 \%} \\
\text { (-) The umbonal angle is expanded while the ante- } \\
\text { roventral angle is curved. Anterior margin bends } \\
\text { away to the posterior fold making its dorsal margin } \\
\text { slightly compressed and its ventral margin elongated. } \\
(+) \text { The anteroventral angle is shortened and pro- } \\
\text { nouncedly curved. The umbonal angle and anterior } \\
\text { margin are tightly compressed to each other resulting } \\
\text { to largely expand dorsal margin and elongated ventral } \\
\text { margin. }\end{array}$ \\
\hline RW4 & & $\begin{array}{l}\text { Variation accounts about } \mathbf{6 . 7 0 \%} \\
\text { (-) The umbonal angle is compressed. While the an- } \\
\text { teroventral angle curved pronouncedly. The dorsal } \\
\text { and anterior margins bend closer to the posterior fold } \\
\text { making its ventral margin compressed. } \\
\text { (+) The umbonal angle is largely expanded while the } \\
\text { anteroventral angle bends inward and shortened. The } \\
\text { ventral margin compressed tightly while the dorsal } \\
\text { margin bends inward and the anterior margin protru- } \\
\text { des outward. }\end{array}$ \\
\hline
\end{tabular}

Table 2. The shell shape variations observed in left and right valves of the pooled populations of $A$. oceanica as outlined by the significant relative warps.

the magnitude of the fluctuation (Figs. 11, 12). PCA tors at landmarks showing the magnitude and direcrevealed that the dominant features of variation re- tion of the displaced landmark while the PC2 exlated to FA in $A$. oceanica populations from both plains the variance via the thin plate splines, an sites were associated with the deformations in the interpolation function that models change between umbonal and anteroventral angles and in the dorsal, landmarks from the data of changes in coordinates anterior and ventral margins of the outer shell. The of landmarks (Marquez, 2014). Herewith, A. oceanpercentage values of PCA represent the level of ica population in Samboang (71.62\%) exhibited variability in the data wherein PC1 elucidates vec- higher level of variability compared in Tulog-bato 


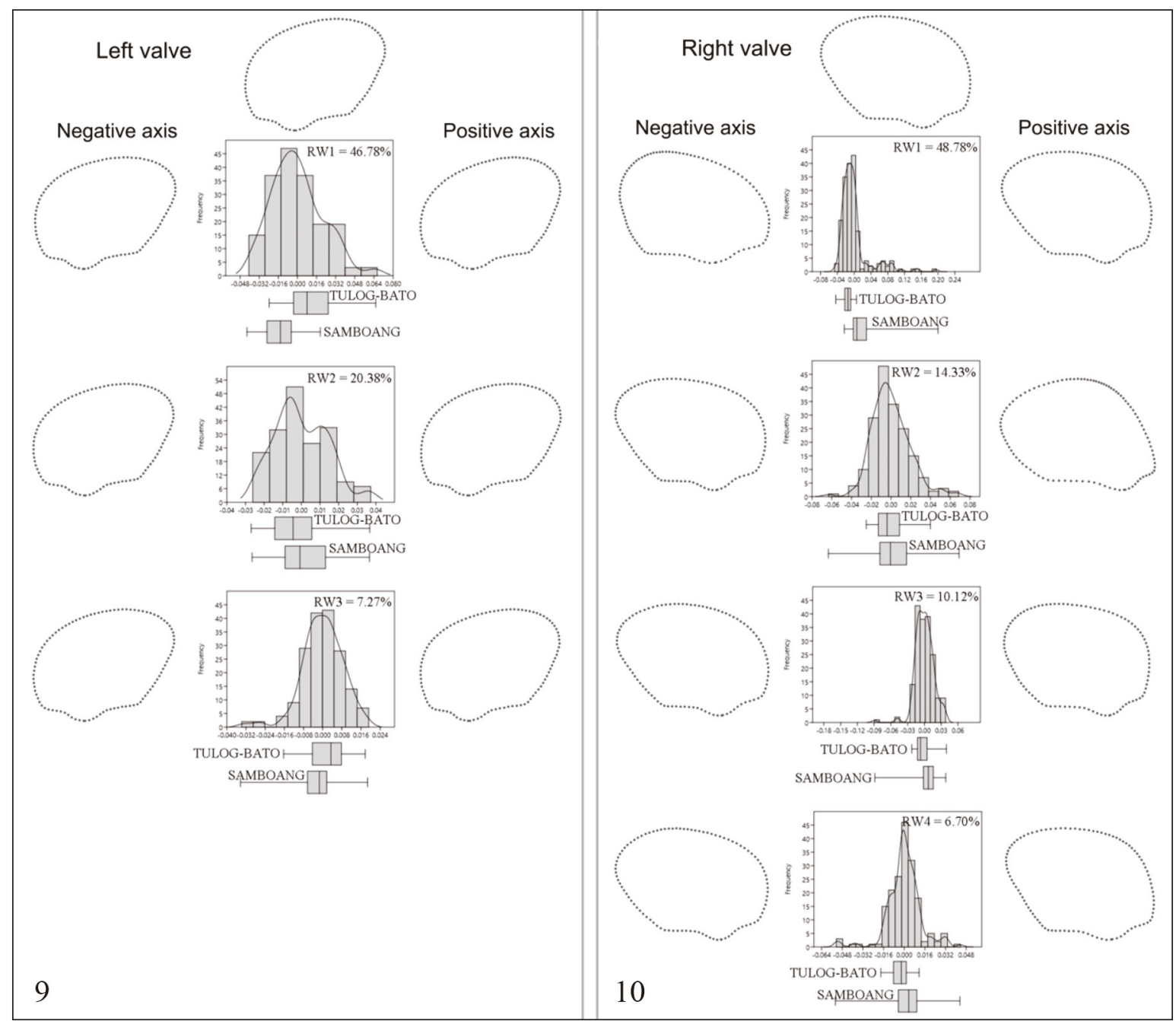

Figures 9, 10. Relative warps showing the boxplot, consensus morphology and the frequency histogram of shell shape variability of the (Fig. 9) left and (Fig. 10) right valves of A. maculosa from the two populations.

population $(54.72 \%)$ based on the overall variation exhibited by PC1 and PC2.

The causes of variations in the shell shapes of bivalves have been the focus of so many debates and for A. oceanica in particular, it should still be subjected to further studies. However, in this case, there could be many underlying factors that may have shaped variations within and between populations. Taking the results as a whole, it was clear that the differences in the shapes between the left and right valves of $A$. oceanica otherwise known as fluctuating asymmetry (FA) was the cause of shell shape variation within population that contributed significantly to the variation between populations. FA is defined as random deviations from perfect symmetry of the morphology of an organism (Palmer, 1994). The variations within and between populations of $A$. oceanica could be genetic in nature resulting to different tolerance to stress. Populations of this species might have experienced developmental perturbations early in life in their respective habitat which resulted to the deviations from bilateral symmetry (Borlaza \& Tabugo, 2018).

Based on field scientific observation during the sampling period, Tulog-bato and Samboang displayed some anthropogenic disturbances. In Tulogbato, human activities such as cutting of mangroves for fuel wood and burning of mangroves for charcoal making are some of the disturbances that con- 


\begin{tabular}{|lccccc|}
\hline \multicolumn{1}{|c}{ Effects } & SS & df & MS & F & $\boldsymbol{p}$ value \\
\hline Tulog-bato population & & & & & \\
Individuals & 0.0163 & 5684 & 0 & 0.675 & $0.0000^{* * *}$ \\
Sides & 0.0346 & 196 & 0.0002 & 41.5773 & $0.0000^{* * *}$ \\
Individuals $x$ Sides & 0.0241 & 5684 & 0 & 0.9572 & $0.0000^{* * *}$ \\
Measurement Error & 0.1043 & 23520 & 0 & --- & --- \\
\hline Samboang population & & & & & \\
Individuals & 0.0828 & 5684 & 0 & 0.8418 & $0.0000^{* * *}$ \\
Sides & 0.0697 & 196 & 0.0004 & 20.553 & $0.0000^{* * *}$ \\
Individuals $x$ Sides & 0.0984 & 5684 & 0 & 1.8904 & $0.0000^{* * *}$ \\
Measurement Error & 0.2154 & 23520 & 0 & --- & --- \\
\hline
\end{tabular}

Table 3. Results of Procrustes Two-Way, Mixed Model Analysis of Variance of the body symmetry of $A$. oceanica from the two populations. Note: Individuals $=$ shape variation, Sides $=$ directional asymmetry; Individuals $\mathrm{x}$ Sides interaction $=$ fluctuating asymmetry; ${ }^{* *} \mathrm{p}<0.001$ - Highly significant, ns- Statistically insignificant ( $\mathrm{p}>0.05$ ); Significance was tested with 99 permutations.

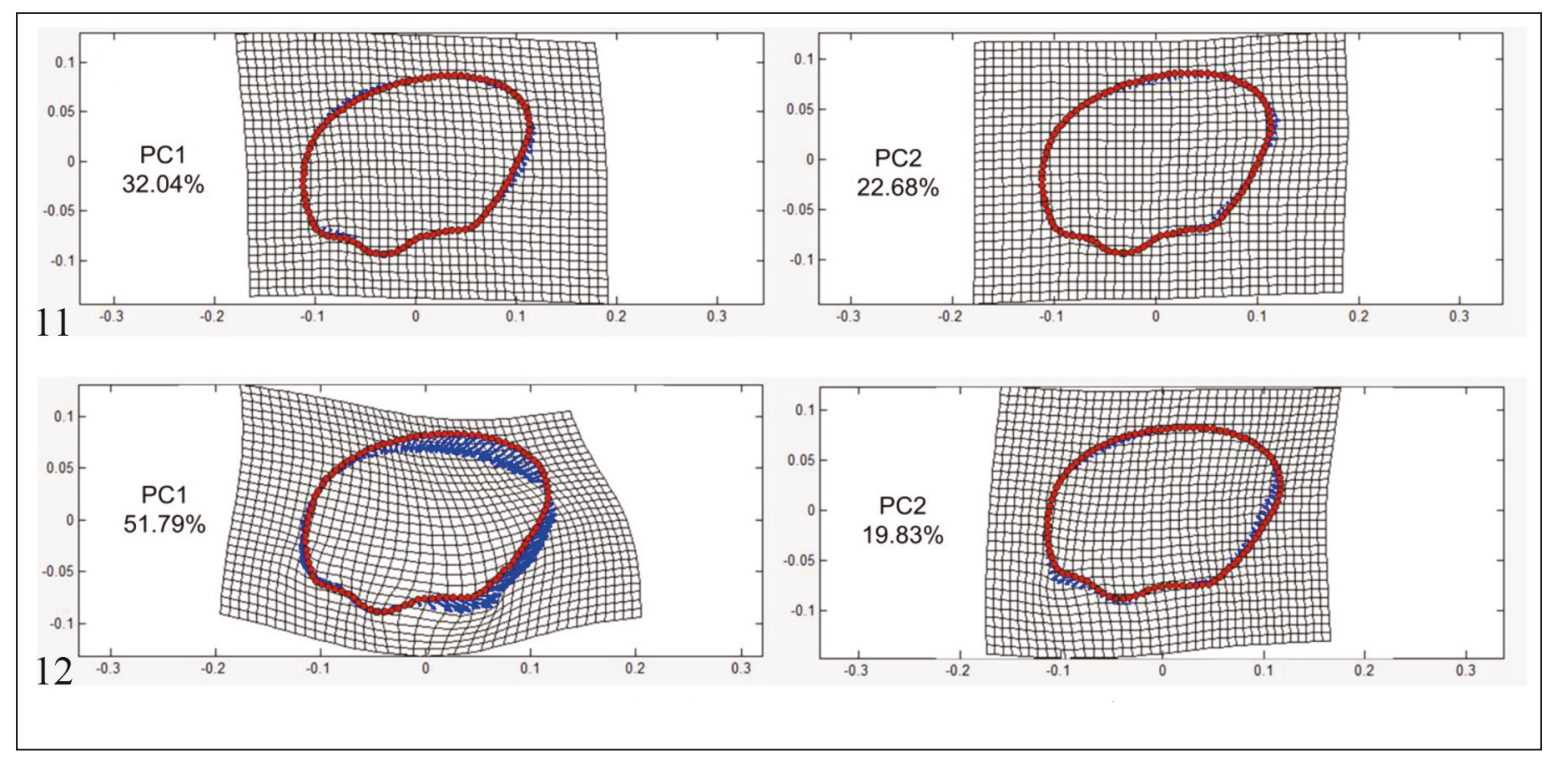

Figures 11, 12. Deformation grids of shell shapes related to fluctuating asymmetry in A. oceanica from Tulog-bato (Fig. 11) and Samboang populations (Fig. 12) based from the first two principal components.

tributed to the destruction of this mangrove estuarine ecosystem. Furthermore, large amount of pollution brought by residential wastes is prevalent in Samboang which are directly disposed the intertidal zones due to the residential houses along the shore and this is evident by the various litter that is frequently found scattered in the coastline such as plastic bottles, plastic sachets and diapers. These anthropogenic disturbances, among others, are the results of the growth of human population (Behera et al., 2014). As A. oceanica populations experienced these disturbances in these areas, they could develop an adaptation either to change its growth form or improve alternative phenotypes to adapt in its current habitat conditions which in return could lead to ecological plastic responses where changes 
in the structure of the shells are the first visible reflections (Qonita et al., 2015). When the habitat is disturbed such as that of in Tulog-bato and Samboang, it leads to inability of an organism to moderate its development against genetic or environmental conditions (developmental instability) (Daloso, 2014). Such development cannot be restored to the original pathway causing slight random deviations in the symmetry and eventually increase phenotypic variations of the organism (Trono et al., 2015).

\section{CONCLUSIONS}

The use of outline-based geometric morphometrics showed significant variations in the shell shapes of the outer left and right valves between populations of $A$. oceanica. Although, these variations should be further studied in order to elucidate their sources. Further investigations revealed that the differences in the shapes between the left and right valves of $A$. oceanica, which is known as fluctuating asymmetry, were the cause of shell shape variation within populations that contributed significantly to the variation between populations. This study clearly proved that shell shape variation does not only occur in geographically isolated populations, it could also occur in neighbouring populations such as that of in Tulog-bato and Samboang. It is hypothesized that shell shape variation is an adaptive strategy of bivalves in response to its current ecological conditions. Thus, shell shape variations in $A$. oceanica populations may have implications to habitat adaptation which can help in understanding the nature of this species especially those inhabiting in the intertidal zones of Margosatubig, Zamboanga del Sur, Philippines.

\section{ACKNOWLEDGEMENTS}

The authors would like to thank the Department of Science and Technology-Science Education Institute Scholarship Program for the scholarship grant; Local Government Unit of Margosatubig, Zamboanga del Sur for the permission to conduct this research in their locality as well as to the locals for collecting the samples. The office of Community Environment and Natural Resources, Zamboanga
City is acknowledged for providing the map of the study site.

\section{REFERENCES}

Adams D.C., Rohlf J.F. \& Slice D.E., 2004. Geometric morphometrics: ten years of progress following the "Revolution". Italian Journal of Zoology, 71: 5-16. https://doi.org/10.1080/11250000409356545

Alibon R.D., Gonzales J.M., Ordoyo A.E. \& Madjos G.G., 2018. Ecophenotypic variation of the common cockle Anadara maculosa populations: implication to microhabitat bio-indication. Journal of Entomology and Zoology Studies, 6: 2706-2710.

Alibon R.D., Gonzales J.M.P., Ordoyo A.E.T., Medalle S.M.D., Abduho A.T., Jingkatal A.M., Cuadra B.E.S. \& Sepe M.C., 2019. Effect of endoparasites in the length-weight relationship and developmental stability of the threadfin bream Nemipterus japonicus (Bloch, 1791). International Journal of Zoology and Applied Biosciences, 4: 174-183. https://doi.org /10.5281/zenodo.3403389

Aydin M., Karadurmus U. \& Tunca E., 2014. Morphometric aspects of growth modeling of exotic bivalve blood cockle Scapharca inaequivalvis from the Black Sea Turkey. Biologia, 69: 1707-1715. https://doi.org /10.2478/s11756-014-0476-3

Behera B., Mishra R.R., Patra J.K., Dutta S.K. \& Thatoi H.N., 2014. Physico-chemical properties of water sample collected from mangrove ecosystem of Mahanadi River Delta, Odicha, India. American Journal of Marine Science, 2: 19-24.

Borlaza K.M.E. \& Tabugo S.R.M., 2018. Fluctuating asymmetry as bioindicator of stress and developmental instability in Perna viridis (Asian green mussel) from the coastal areas in Northern Mindanao, Philippines. International Journal of Biosciences, 12: 342-350. http://dx.doi.org/10.12692/ijb/12.4.342350

Brotohadikusumo N.M., 1994. The ecology of the two species of blood clams Anadara granosa (L.) and Anadara antiquata (L.) in Central Java, Indonesia. Dissertation, University of Wales.

Daloso D.M., 2014. The ecological context of bilateral symmetry of organ and organisms. Natural Science, 6: 184-190. http://dx.doi.org/10.4236/ns.2014.640 22

Davenport J. \& Wong T.M. 1986. Responses of the blood cockle Anadara granosa (L.) (Bivalvia: Arcidae) to salinity, hypoxia and aerial exposure. Aquaculture, 56: 151-162. https://doi.org/10.1016/0044-8486 (86)90024-4

Faulkner P., 2010. Morphometric and taphonomic analysis of granular ark (Anadara granosa) dominated 
shell deposits of Blue Mud Bay, northern Australia. Journal of Archaeological Science, 37: 1942-1952. https://doi.org/10.1016/j.jas.2010.02.021

Finogenova N.L., Kurakin A.P. \& Kovtun O.A., 2013. Morphological differentiation of Anadara inaequivalves. Hydrobiological Journal, 49: 3-11. https:// doi.org/10.1615/HydrobJ.v49.i1.10

Graham J.H., Raz S., Hel-Or H. \& Nevo E., 2010. Fluctuating asymmetry: methods, theory, and applications. Symmetry, 2: 466-540. https://doi.org $/ 10.3390 /$ sym 2020466

Hammer Ø., Harper D.A.T. \& Ryan P.D., 2001. PAST: Paleontological Statistics Software Package for education and data analysis. Palaeontologia Electronica, 4:9. http://palaeo-electronica.org/2001_1/ past/ issue1 - 01.htm

Khiaban N., Haddad K., Mogammadi S. \& Sokhanadan N., 2010. A geometric morphometric study on the host populations of the pod borer, Helicoverpa armigera (Hubner) (Lepidoptera: Noctunidae) in some parts of Iran, Munis Entomology and Zoolology Journal, 5: 140-147.

Klingenberg C.P., Barluenga M. \& Meyer A., 2002. Shape analysis of symmetric structures: quantifying variation among individuals and asymmetry. International Journal of Organic Evolution, 56: 1909-1920. https://doi.org/10.1111/j.0014-3820.2002.tb00117.x

Lodola A., Savini D., Mazziotti C. \& Occhipinti-Ambrogi A., 2011. First record of Anadara transversa (Say, 1822) (Bivalvia: Arcidae) in Sardinian Waters (NW Tyrrhenian Sea). Biologia Marina Mediterranea, 18: 256-257.

Madjos G.G. \& Anies O.S., 2016. Morphometrics approaches to studying phenotypic plasticity in Pomacea canaliculata (golden apple snail). International Journal of Advanced and Applied Sciences, 3: $50-56$.

Madjos G.G. \& Demayo C.G., 2018. Macro-geographic variations of the invasive giant African snail Achatina fulica populations in Mindanao, Philippines. Transactions on Science and Technology, 5: 143-154.

Madjos G.G., Demetillo M., Baguio M. \& Torres M.A., 2015. Phenotypic variations in populations of Pomacea canaliculata (golden apple snail): a case of agroecotypes?. Advances in Environmental StudiesInternational Journal of the Bioflux Society, 7: 432-441.

Markus H., 2010. Compendium of Bivalves. A Full-color Guide to 3'300 of the World's Marine Bivalves. A Status on Bivalvia after 250 years of Research. Hackenheim, 57.

Marquez E., 2014. SAGE: Symmetry and Asymmetry in Geometric Data version 1.21. University of Michigan, Ann Harbor, Michigan, USA.

Meshram A.M. \& Mohite S., 2016. Morphometric study of blood clam, Tegillarca rhombea (Born, 1778). Journal of Fisheries and Livestock Production, 4: 179. https://doi.org/10.4172/2332-2608.1000179

Morais P., Rufino M.M., Reis J., Dias E. \& Sousa R., 2014. Assessing the morphological variability of Unio delphinus (Spengler, 1783) (Bivalvia: Unionidae) using geometric morphometry. Journal of Molluscan Studies, 80: 17-23. https://doi.org/10.1093/ mollus/eyt037

Mzighani S., 2005. Fecundity and population structure of cockles, Anadara antiquata L. 1758 (Bivalvia, Arcidae) from a sandy/muddy beach near Dar es Salaam, Tanzania. Western Indian Ocean Journal of Marine Science, 4: 77-84. https://doi.org/10.4314/ wiojms.v4i1.28475

Palmer A.R., 1994. Fluctuating asymmetry analysis: a primer. In: Developmental Instability: Its Origins and Evolutionary Implications (Markow TA, ed). Kluwer Academic, London, United Kingdom.

Peñaredondo M.A.E. \& Demayo C.G., 2017. Relative warp analysis of the forewings of male dragonfly Neurothemis ramburii. Journal of Informatics and Mathematical Sciences, 9: 1081-1086. http://dx. doi.org/10.26713\%2Fjims.v9i4.1008

Qonita Y., Wardiatno Y. \& Butet N., 2015. Morphological variation in three populations of the pill ark cockle, Anadara pilula (Mollusca: Bivalve) of Java, Indonesia. Aquaculture, Aquarium, Conservation \& Legislation, International Journal of the Bioflux Society, 8: 556-564.

Rohlf F.J., 2004. tpsRelw, relative warps analysis, version 1.36. Department of Ecology and Evolution, State University of New York, Stony Brook.

Sansom R.S., 2009. Phylogeny, classification, and character polarity of the Osteostraci (Vertebrata). Journal of Systematic Paleontology, 7: 95-115. https:// doi.org/10.1017/S1477201908002551

Savriama Y., Klingenberg C.P., 2011. Beyond bilateral symmetry: geometric morphometric methods for any type of symmetry. BMC Evolutionary Biology, 11: 1-24. https:// doi.org/10.1186/1471-2148-11-280

Sepe M.C. \& Demayo C.G., 2014. Quantitative description of head shape dimorphism in the rice black bug Scotinophara sp. using landmark-based geometric morphometric analysis. Journal of Applied Science and Agriculture, 9: 263-270.

Sepe M.C. \& Demayo C.G., 2017. Quantitative description of the hindwings of the different populations of the rice black bug Scotiniphara coarctata using landmark-based geometric morphometrics. Journal of Informatics and Mathematical Sciences, 9: 1053-1060. http://dx.doi.org/10.26713\%2Fjims.v9i4.1003

Sepe M.C., Torres M.A.J., Joshi R.C. \& Demayo C.G., 2019. Describing selected populations of the rice black bugs in the Philippines using Correlation Anal- 
ysis Based on Distances (CORIANDIS). Arthropods, 8: 17-31.

Sharma S., Nayak L., Mohanty U. \& Pati M., 2016. Spatial-temporal variation of benthic community in Gopalpur coastal sediment, east coast of India. The International Journal of Earth and Environmental Sciences, 1: 1-10.

Sithik A.M.A., Thirumaran G., Arumugam R., Ragupathi R., Kannan R. \& Anantharaman P., 2009. Physicochemical parameters of holy places Agnitheertham and Kothandaramar Temple; southeast coast of India. America Eurasia Journal of Scientific Research, 4: 108-116.

Souji S. \& Radhakrishnan T., 2015. New report and taxonomic comparison of Anadara and Tegillarca species of Arcidae (Bivalvia: Arcoidea) from Southeastern coast of India. International Journal of Science and Research, 4: 1817-1824.

Strafella P., Ferrari A., Fabi G., Salvalaggio V., Punzo E., Cuicchi C., Santelli A., Cariani A., Tinti F., Tassetti A. \& Scarcella G., 2018. Anadara kagoshimensis (Mollusca: Bivalvia: Arcidae) in Adriatic Sea: morphological analysis, molecular taxonomy, spatial distribution, and prediction. Mediterranean Marine Science, 18: 443-453. https://doi.org/10.12681/ mms. 1933

Swaddle J.P., 2003. Fluctuating asymmetry, animal be- havior and evolution. Advances in the Study of Behavior, 32: 169-205. https://doi.org/10.1016/S00653454(03)01004-0

Tan K.S., Moneva C.S.O., Barazona C.A., Coronel K.H.I. \& Demayo C.G., 2015. Qualitative and quantitative characterization of some common bivalves: Polymesoda bengalensis, Codakia tigerina and Anodontia edentula. Advances in Environmental Biology, 9: 114-122.

Trono D.J.V., Dacar R., Quinones L. \& Tabugo S.R.M., 2015. Fluctuating asymmetry and developmental instability in Protoreaster nodosus (chocolate chip sea star) as biomarker for environmental stress. Computational Ecology and Software, 5: 119-129.

Uba K.I.N., Montecarlo H.M., Noblezada-Payne M.M.P. \& Quinito G.F., 2019. Sexual dimorphism, asymmetry, and allometry in the shell shape of Modiolus metcalfei (Hanley, 1843) collected from Dumangas, Iloilo, Philippines: a geometric morphometric approach. Computational Ecology and Software, 9: 107-120.

Webster M. \& Sheets H.D., 2010. A practical introduction to landmark-based geometric morphometrics. The Paleontological Society Papers, 16: 163-188. https://doi.org/10.1017/S1089332600001868

WoRMS, 2020. World Register of Marine Species. marinespecies.org 
